\title{
Molecular characterization of antimicrobial resistance in non-typhoidal salmonellae associated with systemic manifestations from India
}

Correspondence
G. A. Menezes
godfredmenezes@gmail.com

Received 18 May 2010

Accepted 1 September 2010

\author{
G. A. Menezes, ${ }^{1,2}$ M. A. Khan, ${ }^{3}$ B. N. Harish, ${ }^{1}$ S. C. Parija, ${ }^{1}$ W. Goessens, ${ }^{3}$ \\ K. Vidyalakshmi, ${ }^{4}$ S. Baliga ${ }^{4}$ and J. P. Hays ${ }^{3}$
}

${ }^{1}$ Department of Microbiology, Institute of National Importance, Jawaharlal Institute of Postgraduate Medical Education and Research (JIPMER), Pondicherry, India

${ }^{2}$ Department of Microbiology, SSR Medical College, Belle Rive, Mauritius

${ }^{3}$ Department of Medical Microbiology and Infectious Diseases, Erasmus MC, 's Gravendijkwal 230, 3015 CE Rotterdam, The Netherlands

${ }^{4}$ Department of Microbiology, Kasturba Medical College Mangalore, Manipal University, Mangalore, India

Extended-spectrum cephalosporins and fluoroquinolones are essential antimicrobials for treating invasive salmonellosis, although emerging resistance to these antimicrobials is of growing concern, especially in India. Therefore, a study was conducted to characterize the antimicrobial susceptibility phenotypes, types of extended-spectrum $\beta$-lactamase (ESBL) gene plasmids and serological relationships of 21 non-typhoidal Salmonella isolates from patients who attended three different hospitals in India from 2006 to 2008. The isolates were cultured from stool, blood and cerebrospinal fluid samples obtained from patients presenting with diarrhoea and accompanying systemic manifestations such as fever, vomiting and meningism. Non-typhoidal Salmonella isolates were investigated using serotyping and antimicrobial susceptibility testing. PCR screening was also performed to detect the $\beta$-lactamase, $q n r$ and aac $\left(6^{\prime}\right)-l b$-cr genes and class 1 integrons. Sequencing for quinolone resistance mutations and plasmid replicon typing were also performed. An antimicrobial resistance microarray was used for preliminary screening and identification of bla pumps was also performed. Ten out of 21 isolates (48\%) possessed the extended-spectrum cephalosporin resistance phenotype, with PCR amplification and sequencing revealing that isolates possessed TEM-1, SHV-12, DHA-1, OXA-1-like and CTX-M-15 ESBL genes. FII plasmid replicons were detected in seven isolates (33\%). The involvement of efflux pumps was detected in four isolates (19\%) resistant to ciprofloxacin. It was concluded that SHV-12-carrying Salmonella serotype Agona may play an important role in ESBL-mediated resistance in nontyphoidal salmonellae in India. The very high percentage (48\%) of ESBL-producing non-typhoidal salmonellae isolated from these patients represents a real and immediate challenge to the effective antimicrobial therapy of Salmonella infections associated with systemic manifestations. Continued surveillance for the presence of ESBL-producing (non-typhoidal) salmonellae in India is essential.

\section{INTRODUCTION}

Non-typhoidal Salmonella is one of the principal pathogens implicated in food-borne gastroenteritis worldwide. In severe infections such as meningitis and septicaemia, antibiotic treatment is essential, with extended-spectrum cephalosporins being used preferentially to treat salmonellosis in children (Threlfall, 2002). However, treatment

Abbreviation: ESBL, extended-spectrum $\beta$-lactamase. failures due to the in vivo acquisition of extended-spectrum $\beta$-lactamase (ESBL) or fluoroquinolone resistance genes in Salmonella isolates are now well established (Whichard et al., 2007). Salmonella species resistant to extendedspectrum cephalosporins have been known since 1988 (Hammami et al., 1991) and may be isolated from hospitals in many different continents including Europe, North and South America, North Africa and countries such as India and South Korea (Weill et al., 2004). Salmonellae have been found to possess a wide variety of ESBL enzymes, 
including TEM, SHV, PER and CTX-M (Gniadkowski, 2001), as well as plasmid-borne AmpC enzymes (e.g. CMY, DHA, ACC-1) (Miriagou et al., 2004). CTX-M enzymes are particularly important in facilitating the ESBL resistance phenotype and have been described in several Salmonella serovars. In fact, 12 out of more than 50 currently known CTX-M enzymes (which are divided into five major phylogenetic groups) have been identified in the genus Salmonella.

Fluoroquinolone resistance is also a growing problem in non-typhoidal salmonellae, with the first report of ciprofloxacin resistance in Salmonella enterica infection (eventually leading to treatment failure) being published in 1990 (Piddock et al., 1990). Since then, there have been reports of ciprofloxacin-resistant isolates being found in many countries, including India, Pakistan, Vietnam and Spain (Nath et al., 2000).

Combined ESBL and fluoroquinolone resistance are major problems in the effective treatment of bacterial infections, both in the community and in the nosocomial setting. This problem is greatly increased when bacterial pathogens such as non-typhoidal salmonellae acquire both ESBL and fluoroquinolone resistance, as the consequences could have important health implications for both livestock and the human community. In order to manage and prevent the spread of antimicrobial resistance, both governing bodies and clinicians require accurate information as to the prevalence and molecular mechanisms of antimicrobial resistance within currently circulating bacterial pathogens. At present, this information tends to be lacking, especially in countries with large populations and unrestricted 'overthe-counter' prescription policies, such as India. Therefore, this study was set up to investigate the extent of antimicrobial resistance, including ESBL and fluoroquinolone resistance, in non-typhoidal salmonellae originating from patients who attended three different hospitals in India. Information was also obtained regarding the circulating serovars of non-typhoidal salmonellae in order to relate these characteristics to specific antimicrobial phenotypes.

\section{METHODS}

Bacterial isolates and serotyping. Twenty-one isolates of nontyphoidal salmonellae were collected from patients attending three different hospitals in India (Pondicherry, Bangalore and Mangalore) from 2006 to 2008 . These represented isolates that were cultured from patients with diarrhoea associated with the systemic manifestations fever, vomiting and meningism. Non-typhoidal salmonellae were isolated from 17 stool cultures, three blood cultures and one cerebrospinal fluid sample. Isolates were initially identified biochemically, followed by confirmation using specific antisera. Serovar determination was performed at the Rijksinstituut voor Volksgezondheid en Milieu, Bilthoven, The Netherlands.

Antimicrobial susceptibility. Antibiotic susceptibility profiles were obtained against 16 antibiotics using the Vitek (bioMérieux) system. The MICs of ceftriaxone and ciprofloxacin were determined using
Etest (AB Biodisk). Isolates were confirmed as ESBL producers via the combination disc method using cefotaxime $(30 \mu \mathrm{g})$ and ceftazidime $(30 \mu \mathrm{g})$ and a disc of cefotaxime + clavulanate $(30 \mu \mathrm{g}+10 \mu \mathrm{g})$ and ceftazidime + clavulanate $(30 \mu \mathrm{g}+10 \mu \mathrm{g}) . A \geqslant 5 \mathrm{~mm}$ increase in diameter of the inhibition zone of the cefotaxime + clavulanate and ceftazidime + clavulanate disc, when compared with the cefotaxime and ceftazidime disc alone, was interpreted as phenotypic evidence of ESBL production (NCCLS, 2000). AmpC $\beta$-lactamase production was measured using cefoxitin (a zone diameter of $<18 \mathrm{~mm}$ was considered to be AmpC-positive). The AmpC disc test for plasmidmediated AmpC $\beta$-lactamase detection was carried out according to a procedure described previously (Singhal et al., 2005). Resistant control strains were used for all ESBL and AmpC $\beta$-lactamase detection methods. For detection of the involvement of efflux pumps, a two-step dilution series of the antibiotics nalidixic acid and ciprofloxacin was made to detect MIC in the absence and presence of the efflux pump inhibitor Phe-Arg- $\beta$-naphthylamide. MIC values were expressed as the highest dilution that inhibited growth, as determined by a lack of opacity in the respective wells of the microtitre plate used. A fourfold or greater reduction in the MIC values after the addition of Phe-Arg- $\beta$-naphthylamide was considered significant (Schumacher et al., 2006).

PCR screening, sequence analysis and IEF. Isolates were screened initially for the presence of TEM and SHV $\beta$-lactamases using a commercially available antimicrobial resistance gene microarray (Check-Points BV). PCR screening and sequencing was performed to identify the $\beta$-lactamase resistance genes $b l a_{\mathrm{TEM}}, b l a_{\mathrm{SHV}}, b l a_{\mathrm{OXA}-1}$ group, bla СтХ-м $_{\text {and }} \mathrm{AmpC}$, as described previously (Karisik et al., 2006; Pérez-Pérez \& Hanson, 2002; Taşli \& Bahar, 2005; Woodford et al., 2006). The mechanism associated with any phenotypic quinolone resistance was determined by investigating nucleotide sequence mutations in the DNA gyrase ( gyrA and gyrB) and DNA topoisomerase IV (parC or parE) genes (Giraud et al., 1999; Komp Lindgren et al., 2003; Renuka et al., 2004). Sequencing was performed using both forward and reverse PCR primers and standard methods on an ABI Prism 3130X1 Genetic Analyzer (Applied Biosystems). The BLASTN program was used for database searching (http://www.ncbi. nlm.nih.gov/BLAST/). Additional sequencing primers were required for $b l a_{\text {TEM }}$ PCR product sequencing (lagging strand 7, 5' -TTACTGTCATGCCATCC-3'; and lagging strand 3, 5'-AGAGAATTATGCAGTGC-3'). PCR primers corresponding to sequences downstream (ORF1) of the bla $a_{\mathrm{CTX}-\mathrm{M}}$ genes (M3 int upp, $5^{\prime}$-TCACCCAGCCTCAACCTAAG-3'; and ORF1 pol M3, 5'-GCACCGACACCCTCACACCT-3') were also used (Eckert et al., 2004). Finally, the PCR products of bla $a_{\mathrm{CTX}-\mathrm{M}}$ were subjected to sequencing using primers CTXM-1 fw multi (5'-AAAAATCACTGCGCCAGTTC- $\left.3^{\prime}\right)$, CTX-M-1 multi (REV)F seq (5'-AACGTGGCGATGAATAAGCT-3') and ORF1 pol M3. Plasmid-mediated quinolone resistance was detected as described previously (Wang et al., 2004). PCR screening for the $a a c\left(6^{\prime}\right)-I b-c r$ gene was performed according to Robicsek et al. (2006). The presence of individual plasmid types was determined by PCR screening of I1, FIA, FIB, FII, A/C, HI1, Frep, K/B and B/0 replicons (Carattoli et al., 2005). The presence or absence of class 1 integrons was determined using $5^{\prime}$ - and $3^{\prime}$-conserved segment primers specific for the variable regions of integrons as described by Lévesque et al. (1995). IEF of $\beta$-lactamase enzymes was performed using standard methods (Paterson et al., 2001).

\section{RESULTS}

The 21 non-typhoidal Salmonella isolates investigated comprised six serovars, namely Salmonella Agona (ten), Salmonella Typhimurium (five), Salmonella Enteritidis (three), Salmonella Senftenberg (one), Salmonella Lexington 
(one) and Salmonella Kirkee (one) (Table 1). Serovars were not linked to a particular hospital. Ten of the 21 isolates were resistant to extended-spectrum cephalosporins (cefotaxime, ceftazidime and ceftriaxone) (Table 2). Of the 10 isolates that exhibited extended-spectrum cephalosporin resistance, three were determined to be resistant to a monobactam (aztreonam), a cephamycin (cefoxitin) and amoxicillin/clavulanic acid. They exhibited intermediate resistance to piperacillin/tazobactam. Phenotypically, 10 of the 21 isolates ( $48 \%$ ) harboured ESBL enzymes, of which three $(30 \%)$ co-produced AmpC enzymes. Seven of the 21 isolates $(33 \%)$ were resistant to nalidixic acid and, of these, two ESBL-producing and two non-ESBL-producing isolates were also found to be resistant to ciprofloxacin. At the serovar level, two of the Salmonella Agona isolates were resistant to extended-spectrum cephalosporins and ciprofloxacin. No resistance to carbapenems was recorded.

Interestingly, nine of the ten ESBL-positive isolates (90\%) belonged to Salmonella serovar Agona (Table 1). ESBL array analysis revealed the presence of ten TEM and nine SHV positives within the 21 isolates, with all TEM-positive isolates being TEM-1-positive, and all SHV isolates being either SHV-12- or SHV-5-positive. IEF experiments showed that the cell extracts of these ten isolates contained $\beta$-lactamases with a corresponding $\mathrm{pI}$ of 5.4 (the $\mathrm{pI}$ of TEM-1) and nine $\beta$-lactamases with a corresponding $\mathrm{pI}$ of 8.2 (the pI of SHV-12). Of the ten ESBL-positive isolates, ten $(100 \%)$, nine $(90 \%)$, two $(20 \%)$ and one $(10 \%)$ of the isolates were found to be TEM-1-, SHV-12-, OXA-1-likeand CTX-M-15-positive, respectively, by PCR amplification and sequence analysis (Tables 1 and 2). Additionally, three ESBL producers (30\%) were co-producers of DHA-1 plasmid-borne AmpC $\beta$-lactamase (Tables 1 and 2). The combinations of $\beta$-lactamases found in the isolates are shown in Tables 1 and 2. The four isolates that were ciprofloxacin-resistant showed phenotypic evidence for the involvement of efflux pumps.

The range of mutations found in the DNA gyrase ( $g y r A$ and gyrB) and DNA topoisomerase IV (parC or parE) genes of the ciprofloxacin (quinolone)-resistant isolates is shown in Table 3. All isolates were negative for $q n r$ genes and all four ciprofloxacin-resistant isolates carried the $a a c\left(6^{\prime}\right)-I b-c r$ gene. Of the isolates carrying the $a a c\left(6^{\prime}\right)-I b-c r$ gene, two were Salmonella Agona and were resistant to extended-

Table 1. Serovar distribution of 21 non-typhoidal salmonellae cultured from patients exhibiting systemic manifestations from Pondicherry, Bangalore and Mangalore, India, from 2006 to 2008

All isolates were cultured from stool specimens apart from isolates B4 (from cerebrospinal fluid) and A19, B5 and B13 (from blood culture).

\begin{tabular}{|c|c|c|c|c|c|c|c|c|c|c|c|}
\hline B3 & Typhimurium & $\mathrm{P}$ & 2008 & $\mathrm{~T}-1$ & & C-15 & & A & & Int & FIA and $\mathrm{FIB}, \mathrm{B} / \mathrm{O}$ \\
\hline B4 & Typhimurium & $\mathrm{P}$ & 2008 & & & & & & & & $\mathrm{FII}_{\mathrm{s}}$ \\
\hline A14 & Typhimurium & M & 2006 & & & & & & & & $\mathrm{FII}_{\mathrm{s}}$ \\
\hline B13 & Agona & $\mathrm{P}$ & 2007 & $\mathrm{~T}-1$ & S-12 & & & & & Int & \\
\hline B22 & Agona & $\mathrm{P}$ & 2007 & $\mathrm{~T}-1$ & S-12 & & & & & & $\mathrm{FII}_{\mathrm{s}}$ \\
\hline B23 & Enteritidis & $\mathrm{P}$ & 2008 & & & & & & & & $\mathrm{FII}_{\mathrm{s}}$ \\
\hline A15 & Enteritidis & M & 2006 & & & & & & Ep & & \\
\hline B16 & Lexington & B & 2008 & & & & & & & & \\
\hline A13 & Senftenberg & M & 2006 & & & & & & Ep & & \\
\hline B17 & Kirkee & B & 2008 & & & & & & & & \\
\hline B8 & Agona & $\mathrm{P}$ & 2008 & $\mathrm{~T}-1$ & S-12 & & $\mathrm{O}-1$ & A & Ep & Int & FIA and FIB \\
\hline B9 & Agona & B & 2008 & $\mathrm{~T}-1$ & S-12 & & $\mathrm{O}-1$ & & Ep & Int & FIA and FIB, B/O \\
\hline B1 & Agona & B & 2006 & $\mathrm{~T}-1$ & S-12 & & & & & & \\
\hline B10 & Agona & B & 2008 & $\mathrm{~T}-1$ & S-12 & & & & & Int & \\
\hline B11 & Agona & B & 2006 & $\mathrm{~T}-1$ & S-12 & & & A & & Int & \\
\hline
\end{tabular}

${ }^{\star} \mathrm{P}$, Pondicherry; M, Mangalore; B, Bangalore.

$\dagger$ T-1, TEM-1; S-12, SHV-12; C-15, CTX-M-15; O-1, OXA-1 group; A, AmpC (DHA-1).

¥Ep, Efflux pump positive based on antibiotic testing (see Methods).

§Int, Class 1 integrons.

IIMajor plasmid incompatibility groups FIA, FIB, FII $_{s}$ and B/O, determined by PCR (Carattoli et al., 2005). 
Table 2. Antimicrobial susceptibility profiles for 21 non-typhoidal Salmonella isolates cultured from patients exhibiting systemic manifestations from Pondicherry, Bangalore and Mangalore, India

Antimicrobial drugs to which isolates were resistant are listed: Ak, amikacin; Ac, amoxicillin/clavulanic acid; A, ampicillin; Cz, cefazolin; Cpm, cefepime; Cn, cefoxitin; Cep, cefpodoxime; Ce, cefotaxime; Ca, ceftazidime; Ci, ceftriaxome; Cu, cefuroxime; C, chloramphenicol; Cf, ciprofloxacin; M, meropenem; Na, nalidixic acid; Pc, piperacillin; Pc/Tz, piperacillin/tazobactam. R, Resistant; S, sensitive; I, intermediate.

\begin{tabular}{|c|c|c|c|c|c|c|c|c|c|c|c|c|c|c|c|c|c|c|c|c|c|}
\hline Isolate & Ak & Ac & $\mathbf{A}$ & $\mathrm{Cz}$ & Cpm & $\mathrm{Cn}$ & Cep & $\mathrm{Ce}$ & $\mathrm{Ca}$ & $\mathrm{Ci}$ & $\mathrm{Cu}$ & $\mathrm{C}$ & Cf & $\mathbf{M}$ & $\mathrm{Na}$ & Pc & $\mathrm{Pc} / \mathrm{Tz}$ & & $\beta$-Lactamase & & \\
\hline B3 & S & $\mathrm{R}$ & $\mathrm{R}$ & $\mathrm{R}$ & S & $\mathrm{R}$ & $\mathrm{R}$ & $\mathrm{R}$ & $\mathrm{R}$ & $\mathrm{R}$ & $\mathrm{R}$ & $\mathrm{R}$ & S & S & S & $\mathrm{R}$ & I & $\mathrm{T}-1$ & C-15 & & A \\
\hline B4 & $\mathrm{S}$ & $\mathrm{S}$ & $\mathrm{S}$ & $\mathrm{S}$ & $S$ & $\mathrm{~S}$ & $S$ & $\mathrm{~S}$ & $\mathrm{~S}$ & $S$ & $\mathrm{~S}$ & $\mathrm{~S}$ & $S$ & $\mathrm{~S}$ & $S$ & $\mathrm{~S}$ & $S$ & & & & \\
\hline B5 & $\mathrm{S}$ & $\mathrm{S}$ & $\mathrm{S}$ & S & S & $\mathrm{S}$ & S & S & $\mathrm{S}$ & S & $\mathrm{S}$ & $\mathrm{S}$ & S & S & $S$ & S & S & & & & \\
\hline A14 & S & S & $\mathrm{S}$ & S & S & S & S & S & $S$ & $S$ & S & $S$ & S & $\mathrm{S}$ & S & S & S & & & & \\
\hline $\mathrm{B} 13$ & $\mathrm{~S}$ & S & $\mathrm{R}$ & $\mathrm{R}$ & S & S & $\mathrm{R}$ & $\mathrm{R}$ & $\mathrm{R}$ & $\mathrm{R}$ & $\mathrm{R}$ & $\mathrm{R}$ & S & S & S & $\mathrm{R}$ & S & $\mathrm{T}-1$ & S- 12 & & \\
\hline A19 & S & $\mathrm{S}$ & $\mathrm{S}$ & S & S & S & S & $S$ & $S$ & $S$ & $S$ & $S$ & S & $S$ & $\mathrm{R}$ & $S$ & S & & & & \\
\hline A16 & $\mathrm{S}$ & $S$ & $\mathrm{~S}$ & $\mathrm{~S}$ & S & S & $S$ & $S$ & $S$ & $S$ & $\mathrm{~S}$ & $S$ & S & $\mathrm{S}$ & $S$ & $\mathrm{~S}$ & S & & & & \\
\hline B22 & $\mathrm{R}$ & $S$ & $\mathrm{R}$ & $\mathrm{R}$ & S & S & $\mathrm{R}$ & $\mathrm{R}$ & $\mathrm{R}$ & $\mathrm{R}$ & $\mathrm{R}$ & $\mathrm{R}$ & S & $S$ & S & $\mathrm{R}$ & S & $\mathrm{T}-1$ & S-12 & & \\
\hline B23 & $S$ & $S$ & $S$ & $S$ & S & S & $S$ & $S$ & $S$ & $S$ & $S$ & $S$ & $S$ & $S$ & $\mathrm{R}$ & $S$ & $S$ & & & & \\
\hline A15 & $S$ & $S$ & $\mathrm{~S}$ & $S$ & S & S & S & $S$ & $S$ & $S$ & $S$ & I & $\mathrm{R}$ & $\mathrm{S}$ & $\mathrm{R}$ & S & S & & & & \\
\hline B16 & $S$ & $S$ & $S$ & $S$ & $S$ & $S$ & $S$ & $S$ & $S$ & $S$ & $S$ & $S$ & $S$ & $S$ & $S$ & $S$ & $S$ & & & & \\
\hline A13 & $S$ & $S$ & $S$ & $S$ & $S$ & $S$ & $S$ & $S$ & $S$ & $S$ & $S$ & $S$ & $\mathrm{R}$ & $S$ & $\mathrm{R}$ & $S$ & $S$ & & & & \\
\hline B17 & $S$ & $S$ & $\mathrm{~S}$ & $\mathrm{~S}$ & S & $\mathrm{S}$ & $S$ & $S$ & $S$ & $S$ & $\mathrm{~S}$ & $S$ & S & $S$ & $S$ & $S$ & S & & & & \\
\hline B14 & $\mathrm{S}$ & $S$ & $\mathrm{~S}$ & $\mathrm{~S}$ & S & $\mathrm{S}$ & S & $\mathrm{S}$ & $\mathrm{S}$ & $S$ & $\mathrm{~S}$ & $S$ & S & $\mathrm{S}$ & $\mathrm{R}$ & $\mathrm{S}$ & S & & & & \\
\hline B21 & I & I & $\mathrm{R}$ & $\mathrm{R}$ & S & S & $\mathrm{R}$ & $\mathrm{R}$ & $\mathrm{R}$ & $\mathrm{R}$ & $\mathrm{R}$ & $S$ & S & $S$ & S & $\mathrm{R}$ & S & $\mathrm{T}-1$ & S-12 & & \\
\hline B7 & $\mathrm{S}$ & $\mathrm{S}$ & $\mathrm{R}$ & I & S & $\mathrm{S}$ & $\mathrm{R}$ & $\mathrm{R}$ & $\mathrm{R}$ & $\mathrm{R}$ & $\mathrm{R}$ & $\mathrm{R}$ & S & $S$ & S & $\mathrm{R}$ & S & $\mathrm{T}-1$ & S-12 & & \\
\hline B8 & $S$ & $\mathrm{R}$ & $\mathrm{R}$ & $\mathrm{R}$ & S & $\mathrm{R}$ & I & $\mathrm{R}$ & $\mathrm{R}$ & $\mathrm{R}$ & $\mathrm{R}$ & $\mathrm{R}$ & $\mathrm{R}$ & $S$ & $\mathrm{R}$ & I & I & $\mathrm{T}-1$ & S-12 & O-1 & A \\
\hline B9 & $\mathrm{S}$ & $S$ & $\mathrm{R}$ & $\mathrm{R}$ & S & $S$ & $\mathrm{R}$ & $\mathrm{R}$ & $\mathrm{R}$ & $\mathrm{R}$ & $\mathrm{R}$ & $S$ & $\mathrm{R}$ & $S$ & $\mathrm{R}$ & I & I & $\mathrm{T}-1$ & S- 12 & O-1 & \\
\hline $\mathrm{B} 1$ & I & I & $\mathrm{R}$ & $\mathrm{R}$ & $S$ & $S$ & $\mathrm{R}$ & $\mathrm{R}$ & $\mathrm{R}$ & $\mathrm{R}$ & $\mathrm{R}$ & $S$ & $S$ & $S$ & $S$ & $\mathrm{R}$ & $S$ & $\mathrm{~T}-1$ & S-12 & & \\
\hline $\mathrm{B} 10$ & $S$ & $S$ & $\mathrm{R}$ & $\mathrm{R}$ & S & $S$ & $\mathrm{R}$ & $\mathrm{R}$ & $\mathrm{R}$ & $\mathrm{R}$ & $\mathrm{R}$ & $\mathrm{R}$ & S & $S$ & S & $\mathrm{R}$ & S & $\mathrm{T}-1$ & S-12 & & \\
\hline B11 & $S$ & $\mathrm{R}$ & $\mathrm{R}$ & $\mathrm{R}$ & $S$ & $\mathrm{R}$ & $\mathrm{R}$ & $\mathrm{R}$ & $\mathrm{R}$ & $\mathrm{R}$ & $\mathrm{R}$ & $\mathrm{R}$ & $S$ & $S$ & $S$ & $\mathrm{R}$ & I & $\mathrm{T}-1$ & S-12 & & A \\
\hline
\end{tabular}

${ }^{\star T}$ T-1, TEM-1; S-12, SHV-12; C-15, CTX-M-15; O-1, OXA-1 group; A, AmpC (DHA-1).

spectrum cephalosporins, with one isolate possessing the ESBL phenotype (SHV-12 with TEM-1 and OXA-1 group) and the other a combined ESBL and AmpC co-producing phenotype (SHV-12 and DHA-1 with TEM-1 and OXA-1 group). In this study, $\mathrm{FII}_{\mathrm{s}}$ replicon plasmids were found in seven $(33 \%)$ and $\mathrm{B} / \mathrm{O}$ replicons in three $(14 \%)$ of the isolates (Table 1). Both FIA and FIB replicons were positive in three $(14 \%)$ of the isolates. Plasmids harbouring I1, A/ C, HI1, Frep and K/B replicons types were not detected. Class 1 integrons were detected in seven $(33 \%)$ of the isolates, which were all ESBL-resistant, but were not associated with a particular serovar.

Finally, antibiotic resistance profiles between ESBL producers tended to be similar, with non-ESBL-producing isolates being much more susceptible to a range of common, clinically useful, antibiotics. In contrast, ESBLproducing isolates tended to be resistant to most antibiotics tested, except for amikacin, cefepime, ciprofloxacin, meropenem and piperacillin/tazobactam.

\section{DISCUSSION}

In India, non-typhoidal salmonellae constitute approximately $20 \%$ of the Salmonella serovars currently circulating, and dissemination of isolates resistant to ESBLs is frequently observed (Kumar et al., 2009). Indeed, in the present study, $48 \%(10 / 21)$ of the non-typhoidal salmonellae associated with systemic manifestations analysed harboured ESBL genes and exhibited an ESBL phenotype, representing a very high percentage of isolates. In contrast, in a recent study in Korea, only $1 \%$ of Salmonella isolates possessed the ESBL phenotype, with ESBL phenotypes showing a switch from TEM- and SHV- to CTX-Mmediated resistance (Park et al., 2010). Although several different serovars were identified, the majority $(90 \%)$ of ESBL producers belonged to the Salmonella Agona serovar, which also represented the most abundant serovar isolated in this study. Salmonella Agona was reported for the first time in 1961 in Ghana (Guinée et al., 1961), although this particular serovar has since been reported in many countries worldwide in both humans and animals. For example, in Brazil, Salmonella Agona has been reported as being the fourth most common Salmonella serovar isolated from non-human sources, and is among the top ten serovars associated with human disease (Tavechio et al., 2002). Furthermore, multidrug-resistant Salmonella Agona has been responsible for at least two hospital outbreaks in paediatric wards (Asensi et al., 1994). In both cases, the strains were found to harbour large plasmids that conferred 
Table 3. Mutations found in the DNA gyrase ( $g y r A$ and $g y r B$ ) and DNA topoisomerase IV (parC or parE) genes of four ciprofloxacinresistant non-typhoidal salmonellae from India

All four isolates were positive for the $a a c\left(6^{\prime}\right)-I b-c r$ gene and efflux pumps and negative for mutations in the gyrB and parE genes. Two nalidixic acid-sensitive control strains (included as negative controls) had no mutations (data not shown).

\begin{tabular}{|c|c|c|c|}
\hline Isolate no./Salmonella serovar & Ciprofloxacin MIC $\left(\mu \mathrm{g} \mathrm{ml}^{-1}\right)$ & Mutations in $g y r A$ & Mutations in parC \\
\hline A13/Senftenberg & $>64$ & Ser83 $\rightarrow$ Tyr, Asp87 $\rightarrow$ Gly & Thr57 $\rightarrow$ Ser, Ser $80 \longrightarrow$ Ile \\
\hline B9/Agona & 32 & Ser83 $\rightarrow$ Leu, Asp87 $\rightarrow$ Asn & Thr57 $\rightarrow$ Ser \\
\hline
\end{tabular}

resistance to multiple antibiotics. Currently, there are few publications from India that have investigated antibiotic resistance in non-typhoidal salmonellae (Jesudason et al., 1988), especially isolates cultured from patients exhibiting systemic manifestations of disease. From our results, it appears that Salmonella Agona may also play an important role in non-typhoidal Salmonella ESBL-mediated resistance in India. More importantly, of particular concern is the fact that two isolates of Salmonella Agona recovered in this study possessed both ESBLs and mutations in the DNA gyrase and DNA topoisomerase IV genes, seriously limiting antimicrobial treatment options.

Nine of the 21 non-typhoidal Salmonella isolates in this study were found to possess the SHV-12-type ESBL gene. SHV-12 is currently one of the most common non-CTX-M ESBLs circulating, and has been identified in many Gramnegative species, including Salmonella serovars (Weill et al., 2004). All of the 10 ESBL producers in our study also possessed the TEM-1 (non-ESBL) $\beta$-lactamase. TEM-1 is the most commonly encountered $\beta$-lactamase in members of the Enterobacteriaceae, and is able to hydrolyse narrowspectrum penicillins and cephalosporins, such as cephalothin and cephaloridine.

Among the isolates studied, three were positive for DHA-1, a plasmid-borne AmpC enzyme first identified in Salmonella Enteritidis isolates from Saudi Arabia in 1992, but now reported in several other countries (Verdet et al., 2006). Finally, a single isolate was positive for the CTX-M15 ESBL enzyme. The ESBL enzymes that tend to be responsible for cephalosporin resistance in the genus Salmonella are TEM and SHV $\beta$-lactamase derivatives, although CTX-M-type ESBLs have recently (although infrequently) been reported. In a study by Rotimi et al. (2008) in Kuwait and the United Arab Emirates, 3.4\% of the Salmonella species studied were found to be CTX-M15-positive.

Replicon-type $\mathrm{FII}_{\mathrm{s}}$ plasmids are associated with Salmonella virulence (Guerra et al., 2002). Plasmids containing $\mathrm{FII}_{\mathrm{s}}$ replicons were the most frequent plasmid types found (33\% isolates), with multiple plasmid types being observed in three isolates only. Ten isolates were negative for all of the replicons tested (Table 1). There was no correlation between carriage of plasmid types and Salmonella serovar.
Sorting of plasmids into incompatibility (Inc) groups is advantageous because specific plasmid types have been associated with virulence and/or antimicrobial resistance (Guerra et al., 2002).

Integrons are genetic agents known to harbour and spread antibiotic resistance determinants in pathogenic bacteria (Rotimi et al., 2008). Interestingly, in our set of nontyphoidal salmonellae, all isolates containing class 1 integrons were ESBL-producing isolates, and integrons have previously been associated with the carriage and spread of ESBL enzymes (Novais et al., 2006).

The antimicrobial resistance ESBL array is a DNA microarray system that offers accurate and rapid detection of ESBL genes. The use of such DNA microarrays for rapid genotypic detection of $\beta$-lactamases could be an important tool for monitoring the spread of ESBL resistance genes within the hospital setting of the future (Grimm et al., 2004).

Salmonella Agona carrying SHV-12 may play an important role in non-typhoidal Salmonella ESBL-mediated resistance in India. Further studies into the current extent of infection with this serovar, as well as its potential to spread into surrounding regions, should be investigated more closely. Continued surveillance of circulating ESBL-producing, as well as fluoroquinolone-resistant, salmonellae is warranted throughout India. Indiscriminate and extended use in animal and human practices has enhanced the emergence and spread of multiresistant bacteria. This resistance can be transferred between animals and humans. Therefore, the cautious use of antibiotics in both human and animals is warranted.

\section{ACKNOWLEDGEMENTS}

The authors wish to thank the following people: Dr P. Nordmann (Hôpital de Bicêtre, Paris, France) for providing the AmpC control strains; Dr A. Carattoli (Istituto Superiore di Sanita, Rome, Italy) for providing the control plasmids for this study; Nicole Lemmens (Erasmus MC, Rotterdam, The Netherlands) for help and advice with PCR screening; and Wouter De Levita and Aneta Karczmarek of Check-Points BV, Wageningen, The Netherlands, for help with the ESBL microarray work. This work was supported financially by a European Union FP6 grant (DRESP2). 


\section{REFERENCES}

Asensi, M. D., Solari, C. A. \& Hofer, E. (1994). A Salmonella Agona outbreak in a pediatric hospital in the city of Rio de Janeiro, Brazil. Mem Inst Oswaldo Cruz 89, 1-4.

Carattoli, A., Bertini, A., Villaa, L., Falbo, V., Hopkins, K. L. \& Threlfall, E. J. (2005). Identification of plasmids by PCR-based replicon typing. J Microbiol Methods 63, 219-228.

Eckert, C., Gautier, V., Saladin-Allard, M., Hidri, N., Verdet, C., OuldHocine, Z., Barnaud, G., Delisle, F., Rossier, A. \& other authors (2004). Dissemination of CTX-M-type $\beta$-lactamases among clinical isolates of Enterobacteriaceae in Paris, France. Antimicrob Agents Chemother 48, 1249-1255.

Giraud, E., Brisabois, A., Martel, J. L. \& Chaslus-Dancla, E. (1999). Comparative studies of mutations in animal isolates and experimental in vitro- and in vivo-selected mutants of Salmonella spp. suggest a counterselection of highly fluoroquinolone-resistant strains in the field. Antimicrob Agents Chemother 43, 2131-2137.

Gniadkowski, M. (2001). Evolution and epidemiology of extendedspectrum $\beta$-lactamases (ESBLs) and ESBL-producing microorganisms. Clin Microbiol Infect 7, 597-608.

Grimm, V., Ezaki, S., Susa, M., Cornelius, K., Schmid, R. D. \& Bachmann, T. T. (2004). Use of DNA microarrays for rapid genotyping of TEM $\beta$-lactamases that confer resistance. J Clin Microbiol 42, 3766-3774.

Guerra, B., Soto, S., Helmuth, R. \& Mendoza, M. C. (2002). Characterization of a self-transferable plasmid from Salmonella enterica serotype Typhimurium clinical isolates carrying two integron-borne gene cassettes together with virulence and drug resistance genes. Antimicrob Agents Chemother 46, 2977-2981.

Guinée, P. A., Kampelmacher, E. H. \& Willems, H. M. (1961). Six new Salmonella types, isolated in Ghana (S. volta, S. agona, S. wa, S. techimani, S. mampong and S. tafo). Antonie van Leeuwenhoek 27, 469-472.

Hammami, A., Arlet, G., Redjeb, S. B., Grimont, F., Hassen, A. B., Rekik, A. \& Philippon, A. (1991). Nosocomial outbreak of acute gastroenteritis in a neonatal intensive care unit in Tunisia caused by multiply drug resistant Salmonella Wien producing SHV-2 $\beta$ lactamase. Eur J Clin Microbiol Infect Dis 10, 641-646.

Jesudason, M., Kurian, T., Periera, S. M., Jayasheela, M. \& Koshi, G. (1988). Isolation of Salmonella Agona (4, 12:f, g, s:) for the first time in India. Indian J Pathol Microbiol 31, 303-305.

Karisik, E., Ellington, M. J., Pike, R., Warren, R. E., Livermore, D. M. \& Woodford, N. (2006). Molecular characterization of plasmids encoding CTX-M-15 $\beta$-lactamase from Escherichia coli strains in the United Kingdom. J Antimicrob Chemother 58, 665-668.

Komp Lindgren, P., Karlsson, A. \& Hughes, D. (2003). Mutation rate and evolution of fluoroquinolone resistance in Escherichia coli isolates from patients with urinary tract infections. Antimicrob Agents Chemother 47, 3222-3232.

Kumar, Y., Sharma, A., Sehgal, R. \& Kumar, S. (2009). Distribution trends of Salmonella serovars in India (2001-2005). Trans R Soc Trop Med Hyg 103, 390-394.

Lévesque, C., Piché, L., Larose, C. \& Roy, P. H. (1995). PCR mapping of integrons reveals several novel combinations of resistance genes. Antimicrob Agents Chemother 39, 185-191.

Miriagou, V., Tassios, P. T., Legakis, N. J. \& Tzouvelekis, L. S. (2004). Expanded spectrum-cephalosporin resistance in non-typhoidal Salmonella. Int J Antimicrob Agents 23, 547-555.

Nath, G., Tikoo, A., Manocha, H., Tripathi, A. K. \& Gulati, A. K. (2000). Drug resistance in Salmonella typhi in North India with special reference to ciprofloxacin. J Antimicrob Chemother 46, 149-150.
NCCLS (2000). Performance Standards for Antimicrobial Disk Susceptibility Tests; Approved Standard, 7th edn, M2-A7. Wayne, PA: National Committee for Clinical Laboratory Standards.

Novais, A., Cantón, R., Valverde, A., Machado, E., Galán, J. C., Peixe, L., Carattoli, A., Baquero, F. \& Coque, T. M. (2006). Dissemination and persistence of $b \operatorname{la}_{\mathrm{CTX}-\mathrm{M}-9}$ are linked to class 1 integrons containing CR1 associated with defective transposon derivatives from $\mathrm{Tn} 402$ located in early antibiotic resistance plasmids of IncH12, IncP1- $\alpha$, and IncFI groups. Antimicrob Agents Chemother 50, 2741-2750.

Park, S. H., Seo, Y. H., Ahn, J. Y., Park, P. H., Kim, K. H., Song, Y. H. \& Kim, J. E. (2010). Characteristics of CTX-M type extended spectrum $\beta$-lactamase producing non-typhoidal Salmonella isolates. Infect Chemother 42, 35-38.

Paterson, D. L., Rice, L. B. \& Bonomo, R. A. (2001). Rapid method of extraction and analysis of extended spectrum $\beta$-lactamases from clinical strains of Klebsiella pneumoniae. Clin Microbiol Infect 7, 709711.

Pérez-Pérez, F. J. \& Hanson, N. D. (2002). Detection of plasmidmediated AmpC $\beta$-lactamase genes in clinical isolates by using multiplex PCR. J Clin Microbiol 40, 2153-2162.

Piddock, L. J. V., Whale, K. \& Wise, R. (1990). Quinolone resistance in Salmonella: clinical experience. Lancet 335, 1459.

Renuka, K., Kapil, A., Kabra, S. K., Wig, N., Das, B. K., Prasad, V. V., Chaudhry, R. \& Seth, P. (2004). Reduced susceptibility to ciprofloxacin and $g y r A$ gene mutation in North Indian strains of Salmonella enterica serotype Typhi and serotype Paratyphi A. Microb Drug Resist 10, 146-153.

Robicsek, A., Strahilevitz, J., Jacoby, G. A., Macielag, M., Abbanat, D., Park, C. H., Bush, K. \& Hooper, D. C. (2006). Fluoroquinolonemodifying enzyme: a new adaptation of a common aminoglycoside acetyltransferase. Nat Med 12, 83-88.

Rotimi, V. O., Jamal, W., Pal, T., Sovenned, A. \& Albert, M. J. (2008). Emergence of CTX-M-15 type extended-spectrum $\beta$-lactamaseproducing Salmonella spp. in Kuwait and the United Arab Emirates. J Med Microbiol 57, 881-886.

Schumacher, A., Steinke, P., Bohnert, J. A., Akova, M., Jonas, D. \& Kern, W. V. (2006). Effect of 1-(1-naphthylmethyl)-piperazine, a novel putative efflux pump inhibitor, on antimicrobial drug susceptibility in clinical isolates of Enterobacteriaceae other than Escherichia coli. J Antimicrob Chemother 57, 344-348.

Singhal, S., Mathur, T., Khan, S., Upadhyay, D. J., Chugh, S., Gaind, R. \& Rattan, A. (2005). Evaluation of methods for AmpC $\beta$-lactamase in Gram negative clinical isolates from tertiary care hospitals. Indian J Med Microbiol 23, 120-124.

Taşli, H. \& Bahar, I. H. (2005). Molecular characterisation of TEMand SHV-derived extended spectrum $\beta$-lactamases in hospital-based Enterobacteriaceae in Turkey. Jpn J Infect Dis 58, 162-167.

Tavechio, A. T., Ghilardi, A. C. R., Peresi, J. T. M., Fuzihara, T. O., Yonamine, E. K., Jakabi, M. \& Fernandes, S. A. (2002). Salmonella serotypes isolated from nonhuman sources in Sao Paulo, Brazil, from 1996 through 2000. J Food Prot 65, 1041-1044.

Threlfall, E. J. (2002). Antimicrobial drug resistance in Salmonella: problems and perspectives in food- and water-borne infections. FEMS Microbiol Rev 26, 141-148.

Verdet, C., Benzerara, Y., Gautier, V., Adam, O., Ould-Hocine, Z. \& Arlet, G. (2006). Emergence of DHA-1-producing Klebsiella spp. in the Parisian region: genetic organization of the $\operatorname{amp} C$ and $a m p R$ genes originating from Morganella morganii. Antimicrob Agents Chemother 50, 607-617.

Wang, M., Sahm, D. F., Jacoby, G. A. \& Hooper, D. C. (2004). Emerging plasmid-mediated quinolone resistance associated with the 
qnr gene in Klebsiella pneumoniae clinical isolates in the United States. Antimicrob Agents Chemother 48, 1295-1299.

Weill, F. X., Demartin, M., Tande, D., Espie, E., Rakotoarivony, I. \& Grimont, P. A. (2004). SHV-12-like extended spectrum $\beta$-lactamaseproducing strains of Salmonella enterica serotypes Babelsberg and Enteritidis isolated in France among infants adopted from Mali. J Clin Microbiol 42, 2432-2437.
Whichard, J. M., Gay, K. \& Stevenson, J. E. (2007). Human Salmonella and concurrent decreased susceptibility to quinolones and extended-spectrum cephalosporins. Emerg Infect Dis 13, 16811688.

Woodford, N., Fagan, E. J. \& Ellington, M. J. (2006). Multiplex PCR for rapid detection of genes encoding CTX-M extended-spectrum $\beta$ lactamases. J Antimicrob Chemother 57, 154-155. 